УДК 621.923

DOI: $\underline{\text { https://doi.org/10.36910/6775-2313-5352-2019-14-20 }}$

Полянский В. И., К. т. н.

ООО «Империя металлов», г. Харьков

\title{
УСЛОВИЯ СНИЖЕНИЯ СИЛОВОЙ НАПРЯЖЕННОСТИ МЕХАНИЧЕСКОЙ ОБРАБОТКИ
}

Теоретически обоснованы условия снижения силовой напряженности механической обработки, состоящие главным образом в повышении коэффициента резания, равного отношению тангенциальной и радиальной составляюших силь резания и зависящего от условий трения на передней и задней поверхностях резияа при точении и от условий трения связки круга с обрабатываемым материалом при илифовании. Теоретически показано, что при точении коэффичиент резания может принимать значительно большие значения, чем при шлифовании. Увеличить коэффициент резания при точении можно уменьшением трения на задней поверхности резиа и применением инструментов из синтетических сверхтвердых материалов, обладающих высокой остротой и низким коэффищиентом трения, а такэе применением современных сборных твердосплавных и керамических режущих инструментом с износостойкими покрытиями. При шлифовании основным путем повышения коэффициента резания является снижение трения связки круга с обрабатываемым материалом и обеспечение высокой остроты режущих зерен, применяя круги из синтетических сверхтвердых материалов, работающие в режиме самозатачивания.

Ключевые слова: механическая обработка, резание, илифование, трение, составляющие силы резания, производительность и качество обработки

Постановка проблемы в общем виде и ее связь с важнейшими научными и практическими задачами. Основным условием повышения эффективности механической обработки является снижение силовой и тепловой напряженностей процесса за счет оптимизации режимов резания и характеристик режущих инструментов. В настоящее время накоплен значительный практический опыт в этом направлении. Однако с применением новых обрабатываемых и инструментальных материалов, повышением требований к точности и качеству обрабатываемых поверхностей деталей постоянно возникают новые задачи определения оптимальных условий обработки с целью повышения производительности и качества. В связи с этим в настоящей работе предложено важное и актуальное теоретическое решение задачи снижения силовой напряженности механической обработки лезвийными и абразивными инструментами. Это позволяет выявить основные факторы, наиболее ответственные за формирование параметров силовой напряженности процесса, и определить условия управления ими для снижения силовой напряженности процесса. Исследования выполнены в соответствии с тематическим планом научно-практических работ ООО «Империя металлов» (г. Харьков).

Анализ последних достижений и публикаций. Вопросам снижения параметров силовой напряженности механической обработки в научно- технической литературе уделено большое внимание $[1,2]$. В работе [3] теоретически установлено, что тангенциальная $P_{z}$ и радиальная $P_{y}$ составляющие силы резания, условное напряжение резания (энергоемкость обработки) $\sigma=P_{z} /(a \cdot \varepsilon)$ всецело зависят от коэффициента резания $K_{\text {рез }}=\operatorname{ctg}(\psi-\gamma)$ :

$$
\begin{gathered}
P_{z}=\frac{2 \cdot a \cdot \theta \cdot \tau_{c \partial b}}{K_{p e 3}} \cdot\left(1+\sqrt{1+K_{p e 3}^{2}}\right) ; \\
P_{y}=\frac{2 \cdot a \cdot 6 \cdot \tau_{c \partial b}}{K_{p e 3}^{2}} \cdot\left(1+\sqrt{1+K_{p e 3}^{2}}\right) ; \\
\sigma=\frac{2 \cdot \tau_{c \partial \theta}}{K_{p e 3}} \cdot\left(1+\sqrt{1+K_{p e 3}^{2}}\right),
\end{gathered}
$$

где $a, b$ - толщина и ширина среза, м; $\psi$ - условный угол трения образующейся стружки с передней поверхностью инструмента, град. ( $\operatorname{tg} \psi=f-$ коэффициент трения); $\gamma$ 
положительный передний угол инструмента, град; $\tau_{c \partial s}-$ предел прочности на сдвиг обрабатываемого материала, Н/м².

Как следует из приведенных зависимостей, увеличение коэффициента резания $K_{\text {рез }}$ приводит к снижению тангенциальной $P_{z}$ и радиальной $P_{y}$ составляющих силы резания, условного напряжения резания (энергоемкости обработки) $\sigma=P_{z} /(a \cdot b)$ и соответственно к повышению эффективности механической обработки. Однако в данном случае расчет коэффициента резания $K_{\text {рез }}=\operatorname{ctg}(\psi-\gamma)$ произведен без учета трения задней поверхности резца с обрабатываемым материалом. Поэтому более полное знание закономерностей

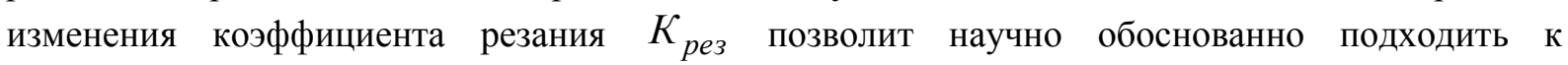
определению условий повышения эффективности механической обработки.

Цель работы - определение путей повышения производительности и качества на основе снижения силовой напряженности механической обработки.

Материалы исследований. В работе [4] приведена аналитическая зависимость для определения отношения тангенциальной и радиальной составляющих силы резания $P_{z} / P_{y}$ при точении с учетом процесса трения на задней поверхности резца при условии $\gamma=0$, которая применительно к процессу точения лопаточным резцом с радиальной подачей (без продольной подачи) принимает вид (рис. 1):

$$
\frac{P_{z}}{P_{y}}=\frac{P_{z_{1}}+P_{z_{2}}}{P_{y_{1}}+P_{y_{2}}}=\frac{P_{z_{1}}+P_{z_{2}}}{f \cdot P_{z_{1}}+\frac{P_{z_{2}}}{f}}=\frac{1+\frac{P_{z_{1}}}{P_{z_{2}}}}{\frac{1}{f}+f \cdot \frac{P_{z_{1}}}{P_{z_{2}}}},
$$

где $P_{z_{1}}, P_{z_{2}}$ - тангенциальные составляющие силы резания, возникающие соответственно на передней и задней поверхностях режущего инструмента, $\mathrm{H} ; P_{y_{1}}, P_{y_{2}}-$ составляющие силы резания $P_{y}$, возникающие соответственные на передней и задней поверхностях режущего инструмента в плоскости уох, Н.

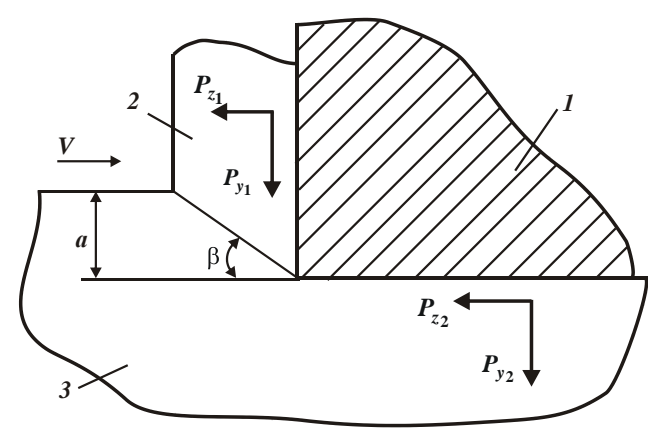

Рис. 1. Расчетная схема параметров процесса точения с учетом трения на задней поверхности резца: 1 - резец; 2 - образующаяся стружка; 3 - обрабатываемый материал ( $\beta$ - условный угол сдвига обрабатываемого материала)

Расчетами установлено, что отношение $P_{z} / P_{y}$ с увеличением отношения $P_{z_{1}} / P_{z_{2}}$ непрерывно увеличивается, начиная со значения $f$, асимптотически приближаясь к значению $1 / f$ (рис. 2). Этим показано, что при точении (при незначительной интенсивности трения на задней поверхности резца) отношение $P_{z} / P_{y}$ может быть больше единицы. В противном случае, т.е. при значительной интенсивности трения на задней поверхности резца, отношение $P_{z} / P_{y}$ меньше единицы, что свидетельствует о низкой эффективности процесса резания затупившимся резцом и согласуется с известными экспериментальными данными. 
Полученное теоретическое решение можно использовать для определения условий снижения силовой напряженности процесса резания лезвийными и абразивными инструментами, что имеет важное научное и практическое значение при решении задач повышения производительности и качества обработки.

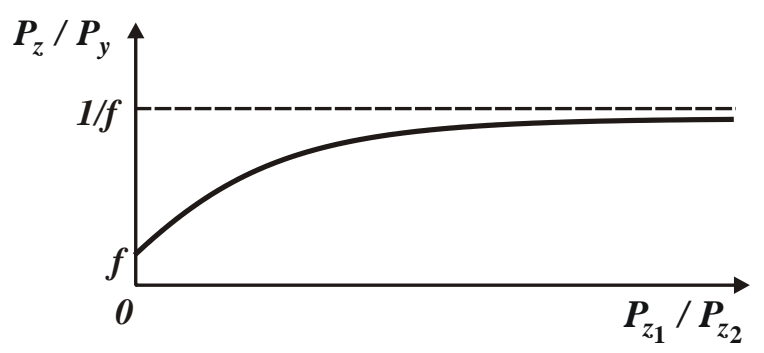

Рис. 2. Зависимость $P_{z} / P_{y}$ от отношения $P_{z_{1}} / P_{z_{2}}$ при условии $\gamma=0$

Как показано в работе [4], при условии $\gamma \neq 0$ характер изменения отношения $P_{z} / P_{y}$ от отношения $P_{z_{1}} / P_{z_{2}}$ описывается зависимостью (рис. 3):

$$
\frac{P_{z}}{P_{y}}=\frac{P_{z_{1}}+P_{z_{2}}}{\frac{P_{z_{1}}}{K_{\text {pes }}}+\frac{P_{z_{2}}}{f}}=\frac{1+\frac{P_{z_{1}}}{P_{z_{2}}}}{\frac{1}{f}+\frac{1}{K_{\text {pes }}} \cdot \frac{P_{z_{1}}}{P_{z_{2}}}} .
$$

В этом случае отношение $P_{z} / P_{y}$ увеличивается от значения $f$ до значения $K_{\text {peз }}=\operatorname{ctg}(\psi-\gamma)$. Наименьшее значение отношения $P_{z} / P_{y}=f$ достигается при значительном затуплении резца (по задней поверхности), когда $P_{z_{1}}<<P_{z_{2}}$.

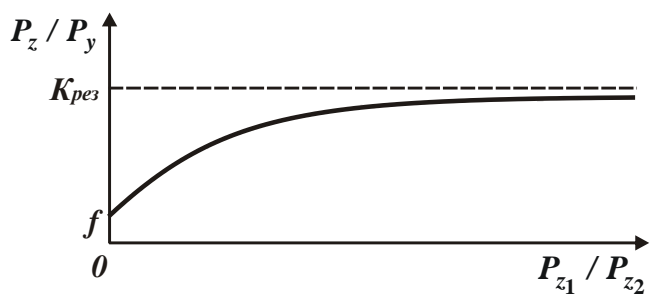

Рис. 3. Зависимость $P_{z} / P_{y}$ от отношения $P_{z_{1}} / P_{z_{2}}$ при условии $\gamma \neq 0$

При условии $P_{z_{1}}>P_{z_{2}}$ отношение $P_{z} / P_{y} \rightarrow K_{\text {рез }}$. В этом случае фактически отсутствует трение на задней поверхности резца, поскольку резание производится острым режущим лезвием резца. Исходя из зависимости $K_{p e з}=\operatorname{ctg}(\psi-\gamma)$, увеличить $K_{\text {рез и }}$ соответственно повысить эффективность обработки можно уменьшением условного угла трения стружки с передней поверхностью резца $\psi$ и увеличением положительного переднего угла резца $\gamma$.

При резании резцом с отрицательным передним углом коэффициент $K_{p e з}=\operatorname{ctg}(\psi+\gamma)$ уменьшается, что повышает силовую напряженность процесса резания и снижает качество и производительность обработки. В этом случае эффективно использовать резцы из синтетических сверхтвердых материалов (СТМ), которые, как правило, применяются при получистовой обработке с небольшими толщинами среза и с фактически отрицательными передними углами. Благодаря небольшому коэффициенту трения СТМ с обрабатываемым материалом, коэффициент $K_{\text {peз }}=\operatorname{ctg}(\psi+\gamma)$ увеличивается и может принимать значения, близкие к единице или больше единицы, что повышает качество и производительность обработки даже при резании резцами со значительными площадками износа, образовавшимися 
на задней поверхности. Эффективно также применять современные режущие твердосплавные и керамические инструменты с износостойкими покрытиями, обеспечивающими высокую режущую способность при высоких температурах резания, что позволяет повысить коэффициент $K_{\text {рез }}$.

Используя полученные решения, можно объяснить причины повышения энергоемкости и силовой напряженности процесса шлифования, обусловленные наличием отрицательных передних углов у режущих зерен. При этом, как известно, в процессе шлифования имеет место интенсивное трение связки круга с обрабатываемым материалом, что приводит к дополнительному повышению силовой и тепловой напряженностей процесса обработки. В этом случае в зависимости (4) вместо коэффициента трения $f$ на задней поверхности резца следует рассматривать коэффициент трения связки круга с обрабатываемым материалом, а вместо коэффициента $K_{\text {рез }}=\operatorname{ctg}(\psi-\gamma)_{-}$значение коэффициента $K_{p e з}=\operatorname{ctg}(\psi+\gamma)$, определяющего процесс резания абразивными зернами без учета трения связки круга с обрабатываемым материалом (рис. 3).

Как и в предыдущем случае, отношение $P_{z} / P_{y}$ изменяется в пределах от значения коэффициента трения связки круга с обрабатываемым материалом $f$ до значения $K_{\text {рез }}=\operatorname{ctg}(\psi+\gamma)$. Очевидно, $\quad$ коэффициент $\quad K_{p e з}=\operatorname{ctg}(\psi+\gamma)<1, \quad$ поскольку $\quad$ угол $(\psi+\gamma)>45^{0}$. Увеличить значение коэффициента $K_{p е з}=\operatorname{ctg}(\psi+\gamma)$ и соответственно повысить эффективность процесса шлифования, исходя из этого, можно уменьшением угла $(\psi+\gamma)$ за счет снижения интенсивности трения режущих зерен с обрабатываемым материалом и уменьшения отрицательного переднего угла зерна $\gamma$, например, за счет применения режущих зерен из СТМ, обладающих высокой остротой и небольшими отрицательными передними углами (менее $30^{\circ}$ ). Кроме того, эти зерна характеризуются весьма небольшим коэффициентом трения с обрабатываемым материалом. В итоге угол $(\psi+\gamma)$ может быть уменьшен до $45^{\circ}$, а коэффициент $K_{\text {рез }}=\operatorname{ctg}(\psi+\gamma) \rightarrow 1$, что подтверждается экспериментальными данными, полученными при алмазном шлифовании [5]. Это позволяет существенно снизить силовую и тепловую напряженность процесса шлифования и повысить качество и производительность обработки (по сравнению с обычным абразивным шлифованием).

Необходимо отметить, что для реализации данного условия следует фактически исключить трение связки круга с обрабатываемым материалом, например, путем применения электроэрозионной или электрохимической правки алмазного круга на металлической связке [5]. В противном случае отношение $P_{z} / P_{y}$ будет принимать относительно небольшие значения, близкие к коэффициенту трения связки круга с обрабатываемым материалом $f$, что снижает эффективность обработки и свидетельствует о преобладании в процессе шлифования трения связки круга с обрабатываемым материалом. Повысить качество и производительность обработки при шлифовании можно применением высокопористых, импрегнированных и прерывистых абразивных кругов, алмазных кругов на относительно малопрочных органических и керамических связках, работающих в режиме самозатачивания и т.д.

Выводы. Аналитически обоснованы условия снижения силовой напряженности механической обработки на основе повышения коэффициента резания, равного отношению тангенциальной и радиальной составляющих силы резания, который при точении зависит от условий трения на передней и задней поверхностях резца, а при шлифовании - от условий трения связки круга с обрабатываемым материалом. Расчетами установлено, что при точении коэффициент резания, как правило, больше единицы, а при шлифовании меньше единицы. Увеличить коэффициент резания при точении можно уменьшением трения на задней поверхности резца, а при шлифовании - уменьшением трения связки круга с обрабатываемым материалом, например, за счет применения синтетических сверхтвердых материалов.

Перспективы дальнейшей работы в данном направлении. В дальнейших исследованиях необходимо определить доли энергий резания и трения в общем энергетическом балансе механической обработки лезвийными и абразивными инструментами и разработать практические рекомендации по снижению силовой напряженности механической обработки. 


\section{Информационные источники}

1. Бобров В. Ф. Основы теории резания металлов / В. Ф. Бобров. - М. : Машиностроение, 1975. -343 c.

2. Якимов А.В. Оптимизация процесса шлифования / А.В. Якимов. - М.: Машиностроение, 1975. - 175 с.

3. Новіков Ф.В. Фінішна обробка деталей різанням: монографія / Ф.В. Новіков, І.О. Рябенков. - Харків: ХНЕУ ім. С. Кузнеця, 2016. - 270 с.

4. Новиков Ф. В. Оценка и анализ долей энергий резания и трения в общем энергетическом балансе процесса механической обработки / Ф. В. Новиков // Резание и инструменты в технологических системах : Междунар. науч.-техн. сб. / Под общ. ред. проф. А. Н. Шелкового, редкол.

А. И. Грабченко (отв. ред.) и др. - Харьков : НТУ «ХПИ», 2018. - Вып. 89(101). - С. 117-125. проф.

5. Сошников С. А. Повышение работоспособности алмазных кругов при шлифовании твердосплавных изделий с прерывистыми поверхностями : автореф. дис. ... канд. техн. наук по специальности 05.03.01 "Процессы и машины обработки материалов резанием; автоматические линии" / С. А. Сошников. - Тула : Тульский политехн. ин-т, 1984. - 23 с.

Полянський В. I., к.т.н.

ТОВ «Імперія металів», м. Харків

\section{УМОВИ ЗНИЖЕННЯ СИЛОВОЇ НАПРУЖЕНОСТІ МЕХАНІЧНОЇ ОБРОБКИ}

Теоретично обгрунтовано умови зниження силової напруженості механічної обробки, які полягають головним чином в підвищенні коефіцієнта різання, рівного відношенню тангенціальної та радіальної складових сили різання, який залежить від умов тертя на передній і задній поверхнях різця при точінні та від умов тертя зв'язки круга з оброблюваним матеріалом при шліфуванні. Теоретично показано, що при точінні коефіцієнт різання може приймати значно більші значення, ніж при шліфуванні. Збільшити коефіцієнт різання при точінні можна зменшенням тертя на задній поверхні різця та застосуванням інструментів із синтетичних надтвердих матеріалів, які характеризуються високою гостротою та низьким коефіцієнтом тертя, а також застосуванням сучасних збірних твердосплавних i керамічних ріжучих інструментів зі зносостійкими покриттями. При шліфуванні основним шляхом підвищення коефіцієнта різання є зниження тертя зв'язки круга з оброблюваним матеріалом і забезпечення високої гостроти ріжучих зерен, застосовуючи круги з синтетичних надтвердих матеріалів, що працюють в режимі самозагострювання.

Ключові слова: механічна обробка, різання, шліфування, тертя, складові сили різання, продуктивність та якість обробки

\section{Polyansky V. I., Ph.D. \\ LLC "Empire of metals", Kharkiv}

\section{CONDITIONS FOR REDUCING THE POWER TENSION OF MECHANICAL} PROCESSING

Theoretically justified are the conditions for reducing the power strength of machining, consisting mainly in increasing the cutting coefficient equal to the ratio of the tangential and radial components of the cutting force and depending on the friction conditions on the front and rear surfaces of the tool when turning and on the conditions of friction of the bundle of a circle with the material being processed during grinding. It is theoretically shown that when turning, the cutting coefficient can take on much larger values than when grinding. Increase the cutting coefficient during turning by reducing the friction on the back surface of the tool and using tools from synthetic superhard materials with high sharpness and low friction, as well as using modern prefabricated carbide and ceramic cutting tools with wear-resistant coatings. When grinding, the main way to increase the cutting coefficient is to reduce the friction of the bundle of the wheel with the material being processed and to ensure high sharpness of the cutting grains, using circles from synthetic superhard materials operating in self-sharpening mode.

Key words: machining, cutting, grinding, friction, component cutting forces, productivity and quality of processing 